\title{
Cloning and Expression of Recombinant Protein MPT63 of Mycobacterium tuberculosis Indonesian Isolate as Serodiagnostic Latent Tuberculosis
}

\author{
Rosana Agus ${ }^{1, *}$ Ian Imanuel Fidhatami ${ }^{1}$ Mochammad Hatta ${ }^{2}$ \\ ${ }^{I}$ Biology Department, Hasanuddin University \\ ${ }^{2}$ Medical Faculty, Hasanuddin University \\ *Corresponding author.Email: rosanagus65@gmail.com,
}

\begin{abstract}
Indonesia and 13 other countries are included in High Burden Countries (HBC) in Tuberculosis (TB) cases. One of the problems in TB control in Indonesia is detecting latent TB appropriately. Diagnosis of latent TB does not have a gold standard. Some tests to detect latent TB have limitations in TB endemic areas such as Indonesia. Therefore, we need a fast, effective, and accurate method to diagnose TB. One of the potential proteins is MPT63, which is coded by the Rv 1926c gene. It is known that MPT 63 can induce Th1 cell reactivity and proliferation of IFN- $\lambda$. The purpose of this research was to clone and produce the recombinant protein MPT 63 from Mycobacterium tuberculosis. The method is Rv 1926c ligation to the pQE30-Xa expression vector and transformation to Escherichia coli BL21 host cell. Recombinant protein production was carried out by growing recombinant clones Rv1926-pQE on Luria Bertani medium by IPTG induction. The transformation results obtained white colonies and blue colonies. The growth of Escherichia coli BL21 carrying a recombinant plasmid is characterized by a change in the color of the medium. MPT63 recombinant protein was characterized by SDSPAGE with a size of $16 \mathrm{kDa}$.
\end{abstract}

Keywords: MPT63, Latent, Serodiagnostic, Recombinant

\section{INTRODUCTION}

People who are infected with Mycobacterium tuberculosis (Mtb) but do not cause clinical signs and symptoms, negative bacteriological tests, normal chest X-rays but positive immunological tests (TST or IGRA) are known as latent tuberculosis infection [1].

People with latent tuberculosis infection (LTBI) can transmit the infection, so a latent TB diagnostic is important to control the spread of TB [2]. No diagnostic gold standard for LTBI. Diagnosis of LTBI can be done by observing the stimulation response in vivo or in vitro by $M t b$ antigen using tuberculin skin test (TST) or Interferon-Gamma Release Assays (IGRAs) [3].

TST and IGRAs depend on cell-mediated immunity (memory T-cell response), and neither test can accurately distinguish between LTBI and active TB disease [4]. The IGRA examination is performed by measuring the immune response to $\mathrm{TB}$ proteins in the blood. The specimen was mixed with a peptide to stimulate the antigen of $M$ tuberculosis. In people who are infected with $\mathrm{TB}$, white blood cells will recognize the antigen that is stimulated to release IFN- $\gamma$, so the results of the IGRA examination are based on the amount of IFN- $\gamma$ released [5].

TST has many limitations, cannot distinguish TB infection or BCG immunization. This test requires 2 patient visits, it takes skills to test and read the test results [6].

The specificity and sensitivity of IGRA are low for detecting active tuberculosis, especially in areas with a high incidence of TB [7]. Studies suggest that IGRA is not recommended as a substitute for TST to predict TB infection in countries with high TB 
prevalence because the results are not significantly different [8]. Due to the limitations of the TST and IGRA tests, it is important to research the diagnostics of latent TB.

One of the recombinant proteins that have the potential to become serodiagnostic latent $\mathrm{TB}$ is MPT63. MPT63 is a secreted protein, specific for mycobacteria, and immunogenic [9]. MPT63 is produced by the $M$. tuberculosis complex and does not have serological cross-reactivity between MPT63 and proteins from other mycobacterial species, so MPT 63 is a candidate for the specific diagnosis of complex M. tuberculosis and vaccines [10].

\section{MATERIALS AND METHODS}

\subsection{Sample}

Mycobacterium tuberculosis was obtained from clinical isolates in Hasanuddin University Medical Research Centre (Hum-RC), Makassar, Indonesia.

\subsection{Preparation of DNA insert and Expression Vector}

Specific primers for $\mathrm{Rv} 1926 \mathrm{c}$ with restriction enzyme sites, BamHI and HindIII were designed. Rv 1926c was amplified using chromosomal DNA from M. tuberculosis by polymerase chain reaction (PCR).

Rv 1926c was amplified with the following primers:

\section{F: 5'CAGCAGGATCCCGCCTATCCCATCACC GGA-3' \\ R: 5'GCCAAGCTTCGGCTCCCAAATCAG CAG-3'}

The PCR reaction was carried out in 30 cycles, consisting of denaturation at $94^{\circ} \mathrm{C}$ for 1 minute, annealing at $56^{\circ} \mathrm{C}$ for 1 minute and extension at $72^{\circ} \mathrm{C}$ for 1 minute. PCR product of $\mathrm{Rv} 1426 \mathrm{c}$ is $412 \mathrm{bp}$, then purified and ready to be ligated to expression vector pQE30 xa and transformed into Escherichia coli $\mathrm{B} 121$

\subsection{Cloning of Rv $1926 c$ gene in E. coli $B L$ 21}

Rv1926c was ligated to the expression vector pQE-30 Xa using DNA T4 ligase and transformed to Escherichia coli BL 21 as in Figure 1. Screening for white and blue colonies was carried out by growing recombinant clones in Luria Bertani and ampicillin medium. Characterization of recombinant clones was carried out by PCR on white colonies and isolation of recombinant plasmids using a plasmid extraction kit.

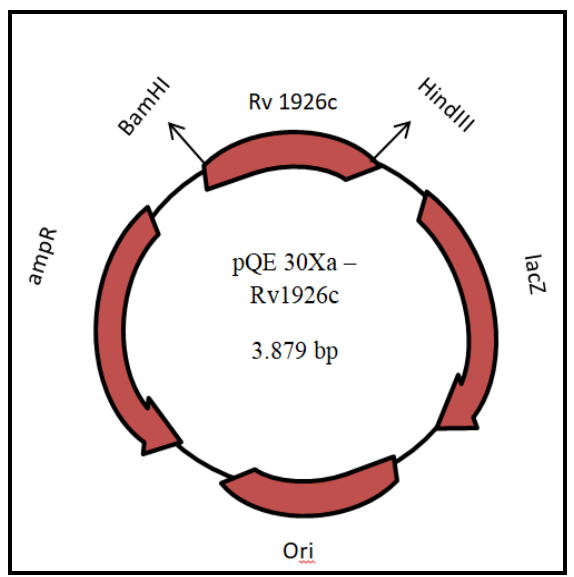

Figure 1. Ligation scheme of Rv1926c into expression vector $\mathrm{pQE}-30 \mathrm{Xa}$

\subsection{Production and purification of the recombinant protein MPT63}

The production of recombinant protein was carried out by growing E. coli transformants in liquid media and induced using IPTG. After being induced, the Escherichia coli transformant cells were broken down using a sonicator. The supernatant containing the product was analyzed by protein electrophoresis. Production is successful when there is a thick protein band measuring $16 \mathrm{kDa}$.

Purification was carried out by affinity chromatography using a nickel column. Protein will be bound to the nickel column through the interaction between His(6) and Ni2+. Then the column is washed with a low concentration of imidazole solution to remove contaminant proteins bound to the column. The pure protein, which remains in the column, is eluted with a high concentration of imidazole solution.

\section{RESULT AND DISCUSSION}

The transformation was carried out using competent Escherichia coli BL 21 cells as an organism that would increase recombinant plasmid. The transformation results obtained white colonies and blue colonies on petridishes containing solid LB medium, IPTG and ampicillin as shown in Figure 2.

Blue-white screening was performed to determine the success of ligation to vector or the presence of DNA insert. The bacterial lac operon contains the lacZ gene which codes for the enzyme $\beta$ - 
galactosidase. The expression vector has a multicloning site (MCS) area in the lac $\mathrm{Z}$ region. If the insert DNA is ligated in this area, the inserted DNA will inhibit the lacZ gene to encode $\beta$-galactosidase so that the enzyme cannot degrade the galactose substrate, the colony will be white. If the DNA insert cannot be ligated, the enzyme can degrade the galactose substrate so that it turns blue. [12]

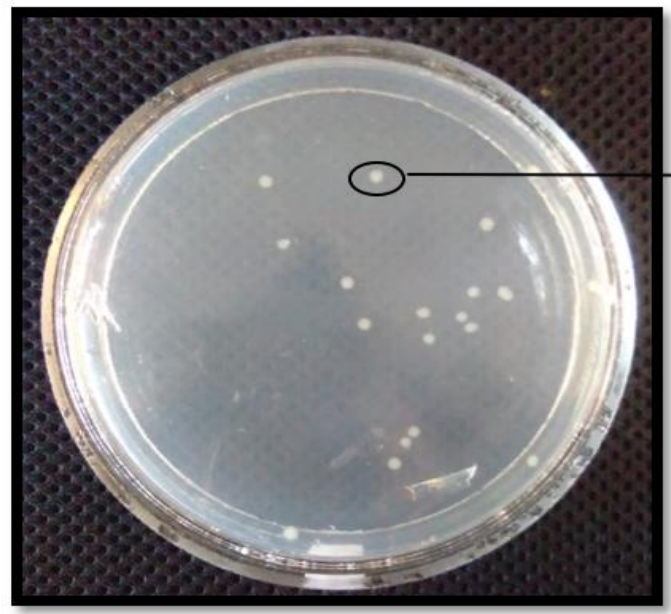

Figure 2. Transformation pQE- Rv1926c into Escherichia coli $\mathrm{BL} 21$

Recombinant clone characterization was carried out on white colonies carrying the Rv 1926c target gene. In white colonies, PCR amplification was carried out under the same conditions before cloning. Electrophoresis of PCR products from recombinant plasmids containing Rv 1926c as DNA inserts with a size of 412 bp. (Figure 3).

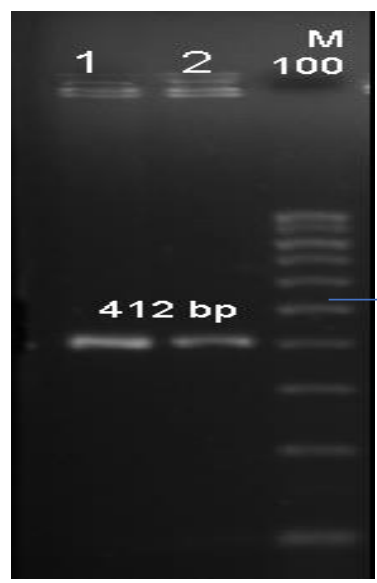

$500 \mathrm{bp}$

Figure 3. PCR colonies.1\&2: Rv 1926c, 412 bp; M: Marker100 bp

White colonies were grown into liquid LB medium with the addition of IPTG and ampicillin. The growth of Escherichia coli BL21 carrying a recombinant plasmid is characterized by a change in the color of the medium (Figure 4).

Production protein of MPT63 in E. coli was most efficient than from Mycobacterium tuberculosis. Escherichia coli BL21 containing recombinant plasmid were cultured in LB medium containing IPTG.

Escherichia coli are host cells commonly used for the production of recombinant proteins in experimental, medical and industrial applications. IPTG is an inducer used to induce a lac promoter for heterologous protein expression [13].

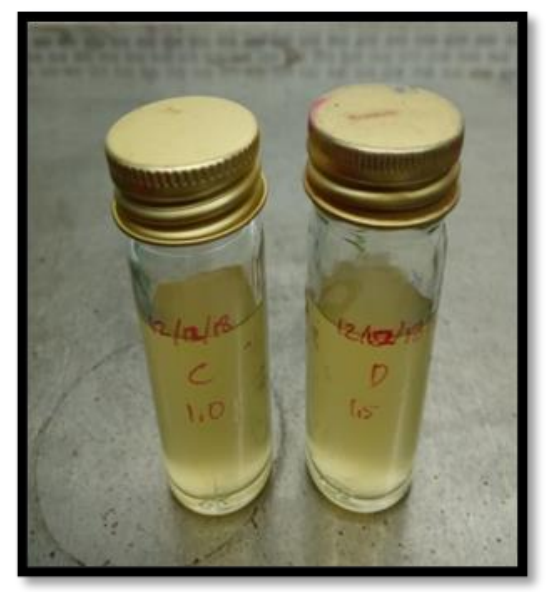

Figure 4. E. coli BL21 carrying a recombinant plasmid pQE- Rv1926c

Lysis of recombinant clone cells was carried out by sonication to obtain MPT63 recombinant protein. MPT63 was characterized by SDS-PAGE and measuring $16 \mathrm{kDa}$ (Figure 5). MPT63 with a molecular weight of $16 \mathrm{kDa}$ is a secreted protein that has a high level of expression in mycobacteria [14].

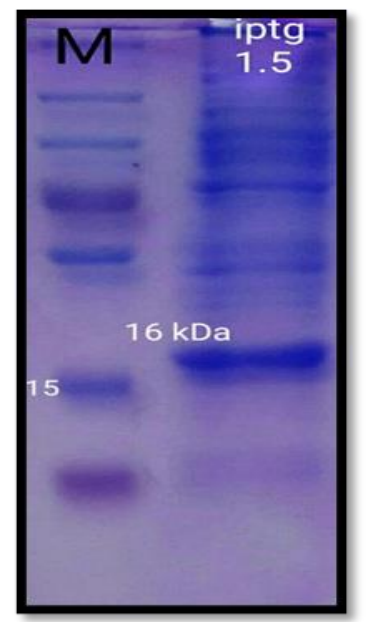

Figure 5. MPT63 recombinant protein 


\section{CONCLUSION}

MPT63 recombinant protein was successfully cloned and produced on Escherichia coli Bl 21 to produce a band measuring $16 \mathrm{kDa}$.

\section{ACKNOWLEDGMENTS}

The author would like to thank the National Research and Innovation Agency of the Republic of Indonesia for funding this research through INSINAS 2020 .

\section{REFERENCES}

[1] World Health Organization, Latent tuberculosis infection: updated and consolidated guidelines for programmatic, 2018.

[2] World Health Organization. Guidelines on the Management of Latent Tuberculosis Infection. 2015.

[3] G. Heileiyesus, A. Matteelli, R.E Chaisson, M. Raviglione. Latent Mycobacterium tuberculosis Infection, Massachusetts Medical Society, 2015, pp 2127-2135, DOI: https://doi.org/10.1056/ NEJMra1405427

[4] M Sester, G.Sotgiu, C.Lange, C. Giehl, E. Girardi, G. B Migliori, A. Bossink, K. Dheda, R. Diel, J.Dominguez, M.Lipman, J.Nemeth, P. Ravn, S.Winkler, E.Huitric, A.Sandgren, D.Manissero, Interferon- $\gamma$ release assays for the diagnosis of active tuberculosis: a systematic review and meta-analysis, PubMed, 2011, pp.100-111, DOI: https://doi.org/ $10.1183 / 09031936.00114810$

[5] Centers for Disease Control and Prevention, Latent Tuberculosis Infection: A Guide for Primary Health Care Providers, 2013.

[6] S.Kiazyk, and TB Ball. Latent tuberculosis: An overview, PubMed, 2017, pp. 62-66, DOI: https://doi.org/10.14745/ccdr.v43i34a01

[7] M.P.C.M Denkinger, S.V Kik, M.X Rangaka, A. Zwerling, O. Oxlade, J.Z. Metcalfe, A. Cattamanchi, D.W. Dowdy, K. Dheda, N. Banaei, Gamma interferon release assays for detection of Mycobacterium tuberculosis infection, PubMed, 2014, pp.3-20, DOI: https://doi.org/ 10.1128/CMR.00034-13
[8] World Health Organization, Tuberculosis IGRA TB tests Policy Statement, 2011.

[9] C.W.Goulding, A. Parseghian, M.R. Sawaya, D. Cascio, M.I. Apostol, M.L Gennaro, D. Eisenberg, Crystal structure of a major secreted protein of Mycobacterium tuberculosis -MPT63 at 1.5- $\AA$ resolution, PMC, 2002, pp.2887-2893, DOI: https://doi.org/ 10.1110/ps.0219002

[10] Z. Duan, D. Li, Q. Jia, J. Xu, X. Chen, Z. Xu, H. Liu, B. Chen, J. Wen, The diagnostic potential of MPT63-derived HLA-A*0201-restricted CD8+ T-cell epitopes for active pulmonary tuberculosis, PubMed, 2015, pp.705-715, DOI: https://doi.org/10.1111/1348-0421.12339

[11] A. Samal, Evaluation of diagnostic potential of recombinant MPT63 protein in bovine tuberculosis, Deemed University Indian Veterinary Research Institute, 2012.

[12] Merck, Blue-White Screening \& Protocols for Colony Selection, 2020.

[13] L. Briand, G. Marcion, A. Kriznik, J. M. Heydel, Y. Artur, C. Garrido, R. Seigneuric \& F. Neiers, A self-inducible heterologous protein expression system in Escherichia coli, PMC, 2016, pp.1-11, DOI: https://doi.org/ $10.1038 /$ srep33037

[14] A.A. Siromolot, O.S. Oliinyk, D.V. Kolibo, S. V. Komisarenko, Mycobacterium tuberculosis antigens MPT63 and MPT83 increase phagocytic activity of murine peritoneal macrophages, PubMed, 2016, pp.62-70, DOI: https://doi.org/ 10.15407/ubj88.05.062 